\title{
Norois
}

Environnement, aménagement, société

$210 \mid 2009 / 1$

L'agriculture et les filières agro-alimentaires en France et en Argentine

\section{Introduction : Agriculture et filières agro- alimentaires en France et en Argentine}

Françoise Ardillier-Carras

\section{(2) OpenEdition}

Journals

Édition électronique

URL : http://journals.openedition.org/norois/2733

DOI : $10.4000 /$ norois. 2733

ISBN : 978-2-7535-1558-1

ISSN : $1760-8546$

Éditeur

Presses universitaires de Rennes

Édition imprimée

Date de publication : 1 mars 2009

Pagination : 11-13

ISBN : 978-2-7535-0844-6

ISSN : 0029-182X

Référence électronique

Françoise Ardillier-Carras, «Introduction : Agriculture et filières agro-alimentaires

en France et en Argentine », Norois [En ligne], 210 | 2009/1, mis en ligne le 01 mars 2011, consulté le

01 mai 2019. URL : http://journals.openedition.org/norois/2733 ; DOI : 10.4000/norois.2733

Ce document a été généré automatiquement le 1 mai 2019.

(c) Tous droits réservés 


\title{
Introduction : Agriculture et filières agro-alimentaires en France et en Argentine
}

\author{
Françoise Ardillier-Carras
}

1 Composé d'un ensemble de 7 articles, ce numéro thématique de Norois ouvre un champ disciplinaire commun aux géographes français et argentins. Il est consacré à l'agriculture et aux industries de transformation agricoles.

2 La première partie est consacrée à la complémentarité entre eau et production agricole. Les risques générés par les phénomènes climatiques extrêmes restent parmi les facteurs qui conditionnent le plus fortement l'activité agricole (M. C. Valenzuela et E. Sosa). Ce volet, inscrit dans l'ensemble des travaux de recherche menés à l'université de Rio Cuarto, étudie les impacts climatiques sur l'agriculture d'une pluviométrie excessive et de la sécheresse. Les deux auteurs ont su mettre en évidence les conséquences sur l'érosion des sols destinés aux cultures de même que les impacts humains et économiques des épisodes excessifs, comme les inondations ayant affecté le sud de la Province de Cordoba. Les conséquences en sont visibles dans les paysages, dans les aménagements hydrauliques et par la prise en compte du facteur risque dans les pratiques culturales de cette région.

3 Avec le thème traditionnel de la maîtrise et de la gestion de l'eau en Limousin ( $\mathrm{F}$. Ardillier-Carras), est évoquée une préoccupation ancienne : comment gérer les manques et les excès dans une région de moyenne montagne caractérisée par une grande variabilité pluviométrique afin de valoriser l'élevage bovin à l'herbe, production spécifique de la région? Au fil de cette approche, apparaissent de nouvelles formes de développement agricole, par la gestion raisonnée de l'eau dans un contexte socioéconomique de région rurale fragile, en déclin. Le sujet est plus que jamais d'actualité dans le contexte d'aide au développement des régions européennes de moyenne montagne. Intégré à un plus vaste champ d'investigations sur l'eau et sa gestion, il souligne les effets de la déprise en zone rurale, et en Limousin particulièrement. 
4 Ces deux articles portant sur des milieux différents ouvrent la voie à des approches complémentaires croisées constructives. Ne peut-on y voir, en effet, l'expression des liens entre l'Homme et l'eau, contextualisées selon qu'il s'agit de situations propres au « nouveau monde » latino-américain ou au « vieux continent » européen?

5 Le second volet traite de l'agriculture et des filières agro-alimentaires. Repenser le territoire à la lumière de la mise en culture du soja, met en scène de nouvelles pratiques agricoles et un mécanisme de recompositions socio-territoriales en Argentine (J. M. Coccaro et G. I. Maldonado). Le processus d'« agriculturisation » de la région pampéenne aujourd'hui sert de dénominateur commun, confirmé ensuite par celui de "sojisation ", et à l'origine d'une nouvelle territorialisation d'une région agricole : la Pampa. Cet article entend ainsi mettre l'accent sur la façon de penser le territoire et non uniquement sur le soja qui, ici, sert de prétexte et d'illustration pour renforcer la réflexion. L'apparence homogène des régions vouées au soja peut cacher des diversités sociales, spatiales, économiques, qui composent un tissu territorial imprégné d'un vécu, d'une culture, d'une histoire, et où s'impriment les influences de divers modes de développement agricole, hérités ou contemporains. La perception des auteurs vis-à-vis de l'évolution en cours témoigne d'une réelle connaissance du sujet et des facteurs intervenant dans le processus de construction territoriale. Elle constitue une véritable contribution, un regard géographique enrichi d'apports théoriques, de concepts et de méthodes d'investigation propres à ce sujet et à la situation argentine.

6 Ce type de référence, ancré sur une conjoncture spécifique, en un moment précis et en un territoire donné sert de repère dans toute démarche comparative. Il s'agit alors, dans ce cas, de capter le processus avec toutes ses déclinaisons - spatiales, sociales, économiques, politiques, environnementales... - et avec ses prolongements dans le temps et dans l'espace. Ainsi en fut-il pour le cycle du café, au Brésil, pour divers « modèles » agricoles en Europe : bovin-lait, caprin, céréalier. La « diagonale caprine » du Poitou, par exemple, ne révèle-t-elle pas, outre des performances d'élevage et de production fromagère, une organisation sociale et économique, une construction territoriale particulières, expressément associées à ce type d'élevage dans ce type de région, à une période donnée ? Autrement dit, il s'agit bien là de formes d'évolution des productions et des pratiques agricoles qui ont marqué non seulement leur époque, mais aussi l'organisation des territoires. Qu'y a-t-il finalement dans l'évolution contemporaine de la Champagne berrichonne, que cet « autrement » né de l'expansion d'une culture et des recompositions sociales et économiques induites par le processus? Et les exemples ne manquent pas en France et dans le monde.

7 Avec l'agro-industrie arboricole - en particulier des agrumes - en Argentine (N. Tadeo) sont abordées des tendances conjoncturelles issues de la mondialisation. La demande en fruits de contre-saison pour l'hémisphère Nord génère une réactivation de la production de fruits frais à destination, notamment, des pays de l'Europe du Nord, et une concentration de capital - surtout étranger - à des fins commerciales pour restructurer le secteur des IAA dans plusieurs régions : Tucuman, Entre Rios, Santa Fé, Buenos Aires... Révolution dans le contexte économique des régions productrices, emprise de grandes firmes agro-alimentaires, restructuration de la hiérarchie sociale parmi la population agricole avec émergence des uns et appauvrissement des autres, tels sont les bouleversements issus d'une évolution inéluctable. Apparaissent clairement les intérêts du grand commerce des marchandises agricoles, fait généralisé dans le monde, et qui commande bien des restructurations en cours. 
8 En revanche, c'est bien au travers de la « situationnalité » ou « effet de la situation » de l'Argentine dans ce contexte mondialisé, et des effets d'une situation au sein du continent latino-américain, que peuvent se mesurer les véritables changements affectant aujourd'hui ces territoires de production agricole.

9 C'est sur un mode identique qu'est abordé le cas des complexes sucre-citron dans la province de Tucuman (E. Cueto). L'auteur renvoie à la restructuration des circuits entre production, transformation et commercialisation. Dans la conjoncture contemporaine, de demande des marchés mondiaux, le regard porté sur ces filières, dont la province de Tucuman assure une large part de la production, met en lumière les liens existant entre exploitants - selon la taille des plantations -, grands groupes liés aux IAA, et politiques économiques de l'État face aux marchés, y compris de contre-saison. De plus, la production agricole s'y trouve confrontée à un dilemme contemporain : faut-il produire pour nourrir les hommes ou bien donner priorité à la production végétale pour les biocarburants? Face aux nouvelles formes de valorisation de productions agricoles nées de la crise des hydrocarbures, le ton est donné : il s'agit bien d'un enjeu planétaire, dont l'exemple de l'agriculture argentine sert de référence.

10 Concilier tradition d'élevage, production identitaire, qualité et commercialisation est un challenge auquel est confrontée l'agriculture française en raison de ses spécificités « de terroir ». La production fromagère de montagne, en France, est un sujet très représentatif de l'avenir d'une filière agricole dans un territoire, ici, le Jura (D. Ricard). Les stratégies de développement de filières fromagères sont au cœur de ce travail avec, comme préoccupation essentielle, la maîtrise des marchés et la rentabilité de la production, donc le revenu des exploitations agricoles. C'est vers un objectif qualitatif que se tournent les acteurs de la filière - par labellisation en AOC - et vers la reconnaissance d'un choix commandé par des valeurs économiques, sociales, régionales afin de préserver l'avenir d'une production animale spécifique de la région.

11 Ce parcours entre des agricultures commandées par des impératifs de même nature, la conquête des marchés mondiaux, est l'occasion de saisir bien des caractères propres à chacun des deux pays, l'Argentine et la France, pour mieux mesurer les situations à la lumière des morceaux choisis présentés ici par leurs auteurs.

Suite logique de ce volet consacré à l'agriculture, dans le numéro 211 de Norois seront mis en évidence les caractères étroits entre l'eau et les besoins de l'activité agricole en France (L. Touchart) et (A. Honneger et S. Ghiotti), avec la pression exercée sur la ressource et les concurrences entre usages, ainsi que les évolutions récentes de la filière endivière française (É. Manouvrier). Cet éclairage est fondamental pour affiner la réflexion et s'intègre totalement dans la thématique croisée entre France et Argentine. 


\section{AUTEUR}

\section{FRANÇOISE ARDILLIER-CARRAS}

EA 1210 CEDETE - Orléans, Université de Limoges, 39E rue C.-Guérin - 87036 Limoges cedex, France,

ardillier.carras@wanadoo.fr 